\title{
Factors influencing quality of life in patients with asthma or chronic obstructive pulmonary disease undergoing physiotherapeutic control at primary care in Chile
}

\author{
DOI: https://doi.org/10.5114/pq.2020.96236
}

\author{
Cinara Sacomori', Mitzi Guerrero-González², Cristian Cabrera-González², Sebastián Moreno-Morales³ \\ José Miguel Torres-Varela ${ }^{3}$, Bryan Alegría-Martinez ${ }^{3}$, Luz Alejandra Lorca P. ${ }^{2}$, Thuane Da Roza ${ }^{4}$ \\ ${ }^{1}$ School of Kinesiology, Universidad Bernardo O'Higgins, Santiago de Chile, Chile \\ 2 Servicio de Salud Metropolitano Oriente, Santiago de Chile, Chile \\ ${ }^{3}$ School of Kinesiology, Universidad Andrés Bello, Santiago de Chile, Chile \\ ${ }^{4}$ Laboratory of Biomechanics, Centre for Health and Sports Sciences, Universidade do Estado de Santa Catarina, \\ Florianópolis, Brazil
}

\section{Abstract}

Introduction. The study aimed to determine if quality of life was affected by urinary symptoms, respiratory and emotional functions, or socio-demographic variables among people with chronic respiratory diseases who attended a healthcare visit in a primary care program in Santiago de Chile.

Methods. The observational cross-sectional study included 93 patients (62 with asthma and 31 with chronic obstructive pulmonary disease). Chronic Respiratory Questionnaire was used to assess the quality of life, and a self-report questionnaire reported the comorbidities (arterial hypertension, depression, diabetes mellitus, and lower back pain). The International Consultation on Incontinence Questionnaire-Short Form and the modified Medical Research Council dyspnoea scale served to assess urinary incontinence and respiratory symptoms, respectively. Data were analysed with hierarchical multiple linear regression.

Results. Urinary incontinence occurred in $31.2 \%$ of the participants, mainly while coughing or sneezing $(n=24)$. Around $66.6 \%$ of them self-reported their health status as regular/bad/very bad. The presence of urinary incontinence, depression, and higher dyspnoea $\left(R^{2}=0.54\right)$ was associated with worse quality of life.

Conclusions. Urinary incontinence, depressive symptoms, and higher dyspnoea negatively impact on the quality of life of people with chronic respiratory diseases and require more attention in clinical management and research.

Key words: asthma, chronic obstructive pulmonary disease, physiotherapy, quality of life

\section{Introduction}

Asthma and chronic obstructive pulmonary disease (COPD) negatively affect health-related quality of life [1, 2]. In Chile, $24.5 \%$ of the total population has chronic respiratory symptoms, and $20 \%$ of the total adult consultations in the primary care setting are due to respiratory causes [3]. Studies have demonstrated that these disorders can lead to depression and anxiety [4-7], as well as could result in unemployment and/or a high level of disability [1]. Concerning this, Chile has a special programme administered in primary care settings that shows good results at controlling these chronic conditions in adults $[3,8]$.

Some patients with respiratory diseases experience frequent episodes of coughing or sneezing, which produce an excessive increase in intra-abdominal pressure, and in the long run could lead to lower back pain [9] or urinary incontinence (UI), specially stress UI [10, 11]. Since UI also negatively affects the quality of life, patients with respiratory problems could have an even worse quality of life.

In addition, comorbidities or multimorbidity can impair health-related quality of life. Approximately $86-98 \%$ of individuals with COPD have at least one comorbid condition [5]. Accordingly, 2 indexes have been developed to evaluate comorbidities in people with COPD: the COPD-specific comor- bidity test (COTE) to predict mortality [12] and the COMCOLD index to predict health status [7]. However, these instruments do not include Ul or lower back pain as associate symptoms.

This study aimed to investigate if the quality of life was affected by urinary symptoms, respiratory and emotional functions, or socio-demographic variables among people with chronic respiratory diseases who attended a healthcare visit in a primary care program supervised by physiotherapists in Santiago de Chile.

\section{Subjects and methods}

\section{Design}

An observational cross-sectional study was performed. Data were collected between October 2015 and April 2016. The Strengthening the Reporting of Observational Studies in Epidemiology (STROBE) recommendations were followed.

\section{Participants}

The study included 93 patients with chronic respiratory diseases (asthma or COPD) who attended a healthcare visit in one of two family healthcare centres - Lo Hermida or La Faena - in the Santiago Metropolitan Region in Chile. These

Correspondence address: Cinara Sacomori, Universidad Bernardo O’Higgins, School of Kinesiology, Santiago de Chile Avenida Viel 1497, Santiago de Chile, Chile, e-mail: csacomori@yahoo.com.br 
patients participated in a special Chilean programme administered in primary care settings with the goal of controlling adult chronic respiratory diseases, including regular controls with respiratory physiotherapists. In 2015, 600 patients participated in this program at Lo Hermida and 589 at La Faena. The study involved a non-probabilistic convenience sample.

For sample size, we assumed a minimum of 7 events per variable included in the regression analysis [13]. All participants older than 18 years who attended the controls during the research data collection were included. Patients were excluded if they presented a neurologic disorder or if they were illiterate.

\section{Instruments}

COPD was diagnosed with spirometry showing an obstructive compromise that did not modify after bronchodilator inhalation [3]. Asthma was diagnosed on the basis of spirometry and flowmetry before and after bronchodilator inhalation [8]. The participant should have had a positive diagnosis for one of the above disorders to be included in the study.

The Chronic Respiratory Questionnaire (CRQ) [14] was used to assess the quality of life. The questionnaire has been validated for Chilean patients [15] and presents a good internal consistency (Cronbach $\alpha$ : 0.60-0.89). CRQ contains 20 questions divided into 4 domains: dyspnoea, fatigue, emotional function, and the feeling of control over the disease. For each item, a 7-point Likert response scale is available, with 1 corresponding to the worst function and 7 standing for the best function. The general score and the scores for each domain are calculated $[14,15]$.

Respiratory symptoms were assessed with the modified Medical Research Council (mMRC) dyspnoea scale, which requires individuals to report the degree of activity that results in breathlessness (e.g. walking up a flight of stairs) [16]. The frequency of cough was evaluated with a question that contained the following answer options: never, once per week, 2-3 times per week, once per day, many times per day, and continually.

To assess UI, we used the International Consultation on Incontinence Questionnaire-Short Form (ICIQ-UI-SF). This questionnaire was developed by Avery et al. [17] and has been validated in the Spanish language [18]. The assessment includes questions regarding the frequency and amount of urine loss, the impact of UI in the patients' lives, and the situations in which UI occurs. The final score ranges from 0 to 21 , with higher values representing worse UI. The nocturia symptom was evaluated with the question 'How many times during sleeping hours do you wake up to urinate?'

Socio-demographic (gender, age, education level, and marital status) and clinical data (health status and sleep quality) were obtained by self-report. Comorbidities, such as arterial hypertension, depression, diabetes mellitus, and lower back pain, were evaluated by a self-report questionnaire using 'yes' or 'no' as answer options. Body mass and height were measured with body mass scales and a stadiometer, respectively.

\section{Data analysis}

Statistical analyses were performed with the SPSS software, version 20 (SPSS Inc., Chicago, USA, 2011). Descriptive analysis was used to report frequencies, means, medians, standard deviations, and interquartile ranges. An independent sample $t$-test served to compare asthma and COPD patients with regard to body mass index. Multiple linear regression analysis was applied to obtain associated factors. Pearson correlation coefficients for pairs of dependent and predictor variables were calculated. The data met the assumptions for regression analyses, which concerned linearity and normality of residuals, normal dependent variable, homoscedasticity (i.e. the residuals graph showed a random distribution of the points around 0), and no perfect multicollinearity. The variance inflation factor was calculated to assess multicollinearity; values above 10 were considered an indication of multicollinearity [19]. Also, we used the value of $<0.95$ as a criterion to accept bivariate correlations between variables [19]. The significance was set at $p<0.05$.

The hierarchical regression model included 3 blocks: (1) socio-demographic (sex and age); (2) self-reported comorbidities (UI, hypertension, diabetes, low back pain, and depression); and (3) factors related to respiratory function (frequency of cough and dyspnoea).

\section{Ethical approval}

The research related to human use has complied with all the relevant national regulations and institutional policies, has followed the tenets of the Declaration of Helsinki, and has been approved by the Ethical Committee of the Metropolitan Orient Health Service, Hospital del Salvador, on September 22, 2015.

\section{Informed consent}

Informed consent has been obtained from all individuals included in this study.

\section{Results}

\section{Characteristics of the study participants}

The participants' mean age was $62.6 \pm 18.1$ years and their body mass index equalled $29.9 \pm 5.6 \mathrm{~kg} / \mathrm{m}^{2}$. Most patients had asthma (66.7\%), were female $(77.4 \%)$, had a low level of education (8 years or less: $59.2 \%$ ), and self-reported their health status as regular/bad/very bad (66.6\%). The majority answered that they had lower back pain (55.9\%) or hypertension $(67.7 \%)$ as an associated factor. Overall, 39 patients $(41.9 \%)$ were obese and $33(35.5 \%)$ were overweight (Table 1). Individuals with asthma had a significantly higher body mass index (mean $=31.5 ; S D=5.8$ ) compared with those with COPD (mean $=27.9 ; S D=5.7 ; t=2.8 ; p=0.006)$.

\section{Respiratory symptoms: modified Medical Research Council dyspnoea scale}

Cough was present in $86 \%$ of the patients. Among participants with dyspnoea, $11.8 \%$ reported being too breathless to leave the house or too breathless when dressing or undressing, $25.8 \%$ reported having to make stops to breathe after walking 100 yards, and $25.8 \%$ reported walking slower than people of the same age on the level or stopping for breath while walking at one's own pace on the level. A total of $54.8 \%$ of the patients reported that their sleep quality was regular/ $\mathrm{bad} /$ very bad.

\section{Quality of life: Chronic Respiratory Questionnaire}

Table 2 presents the final score and the scores for the following domains of the CRQ questionnaire: dyspnoea, fatigue, emotional function, and disease control. 
Table 1. Characteristics of the study participants: type of respiratory disease, socio-demographics, comorbidities, sleep quality, health status, and frequency of cough and dyspnoea $(n=93)$

\begin{tabular}{|c|c|}
\hline & $n(\%)$ \\
\hline \multicolumn{2}{|l|}{ Diagnosis } \\
\hline Chronic obstructive pulmonary disease & $31(33.3)$ \\
\hline Asthma & $62(66.7)$ \\
\hline \multicolumn{2}{|l|}{ Sex } \\
\hline Female & $72(77.4)$ \\
\hline Male & $21(26.6)$ \\
\hline \multicolumn{2}{|l|}{ Education level $^{\#}$} \\
\hline Basic incomplete & 18 (19.4) \\
\hline Basic complete & $37(39.8)$ \\
\hline Secondary incomplete & $15(16.1)$ \\
\hline Secondary complete & $12(12.9)$ \\
\hline University incomplete & 5 (5.4) \\
\hline University complete & $3(3.2)$ \\
\hline \multicolumn{2}{|l|}{ Marital status ${ }^{\#}$} \\
\hline Without partner & $44(47.3)$ \\
\hline With partner & $47(50.5)$ \\
\hline \multicolumn{2}{|l|}{ Body mass index\# } \\
\hline Normal & $14(15.1)$ \\
\hline Overweight & $33(35.5)$ \\
\hline Obese & $39(41.9)$ \\
\hline \multicolumn{2}{|l|}{ Comorbidities } \\
\hline Diabetes mellitus & $25(26.9)$ \\
\hline Arterial hypertension & $63(67.7)$ \\
\hline Depression & $31(33.3)$ \\
\hline Urinary incontinence & $29(31.2)$ \\
\hline Lower back pain & $52(55.9)$ \\
\hline Smoker & $8(8.6)$ \\
\hline Ex-smoker & $47(50.5)$ \\
\hline \multicolumn{2}{|l|}{ Cough frequency } \\
\hline Never & $13(14.0)$ \\
\hline Once a week & $17(18.3)$ \\
\hline $2-3$ times a week & $10(10.8)$ \\
\hline Once a day & $4(4.3)$ \\
\hline Many times a day & $29(31.2)$ \\
\hline Continually & $20(21.4)$ \\
\hline \multicolumn{2}{|l|}{ Dyspnoea } \\
\hline Too breathless to leave the house or too breathless when dressing or undressing & $11(11.8)$ \\
\hline Stops for breath after walking 100 yards & $24(25.8)$ \\
\hline Walks slower than people of the same age on the level or stops for breath while walking at own pace on the level & $24(25.8)$ \\
\hline Short of breath when hurrying on the level or walking up a slight hill & $20(21.5)$ \\
\hline Breathless with strenuous exercise & $14(15.1)$ \\
\hline \multicolumn{2}{|l|}{ Self-reported health status } \\
\hline Very good & $1(1.1)$ \\
\hline Good & $30(32.3)$ \\
\hline Regular & $42(45.2)$ \\
\hline $\mathrm{Bad}$ & $15(16.1)$ \\
\hline Very bad & $5(5.3)$ \\
\hline \multicolumn{2}{|l|}{ Sleep quality } \\
\hline Very good & $16(17.2)$ \\
\hline Good & $26(28.0)$ \\
\hline Regular & $25(26.9)$ \\
\hline Bad & $22(23.7)$ \\
\hline Very bad & $4(4.2)$ \\
\hline \multicolumn{2}{|l|}{ Nocturia } \\
\hline None & $23(24.7)$ \\
\hline Wake up to urinate $1-2$ times a night & $39(42.0)$ \\
\hline Wake up to urinate $\geq 3$ times a night & $31(33.3)$ \\
\hline
\end{tabular}


Table 2. Quality of life in patients with chronic respiratory diseases $(n=93)$

\begin{tabular}{|l|l|c|}
\cline { 2 - 3 } \multicolumn{1}{c|}{} & Mean (SD) & Median (IQR) \\
\hline Dyspnoea (range: 5-35) & $17.5(6.8)$ & $17.0(9.8)$ \\
\hline Fatigue (range: 4-28)* & $17.7(6.6)$ & $18.5(11.8)$ \\
\hline Emotional function (range: 7-49) & $30.7(10.8)$ & $31.0(19)$ \\
\hline Disease control (range: 4-28)* & $20.0(6)$ & $21.0(11)$ \\
\hline Total score for quality of life (range: 20-140) & $86.4(25.3)$ & $84.0(38)$ \\
\hline
\end{tabular}

$S D$ - standard deviation, $I Q R$ = interquartile range

* Higher scores indicate better quality of life.

Table 3. Frequency, intensity, and impact of urinary incontinence in the daily life of women with asthma or COPD $(n=29)$

\begin{tabular}{|c|c|c|c|}
\hline Characteristics & $\begin{array}{c}\text { All } \\
(n=29)\end{array}$ & $\begin{array}{l}\text { COPD } \\
(n=8)\end{array}$ & $\begin{array}{l}\text { Asthma } \\
(n=21)\end{array}$ \\
\hline & $n(\%)$ & $n(\%)$ & $n(\%)$ \\
\hline $\begin{array}{l}\text { Frequency of urinary incontinence } \\
\text { Once a week or less } \\
\text { 2-3 times a week } \\
\text { Once a day } \\
\text { Several times a day } \\
\text { All the time }\end{array}$ & $\begin{array}{l}9(31.0) \\
2(6.9) \\
3(10.3) \\
8(27.6) \\
7(24.1)\end{array}$ & $\begin{array}{l}2(25.0) \\
1(12.5) \\
0 \\
1(12.5) \\
4(50.0)\end{array}$ & $\begin{array}{l}7(33.3) \\
1(4.8) \\
3(14.3) \\
7(33.3) \\
3(14.3)\end{array}$ \\
\hline $\begin{array}{l}\text { Amount of urine leakage } \\
\text { Small } \\
\text { Moderate } \\
\text { Large }\end{array}$ & $\begin{array}{c}11(37.9) \\
16(55.2) \\
1(3.4)\end{array}$ & $\begin{array}{l}3(37.5) \\
5(62.5) \\
0\end{array}$ & $\begin{aligned} 8 & (38.1) \\
11 & (52.4) \\
1 & (4.8)\end{aligned}$ \\
\hline $\begin{array}{l}\text { How much does urinary incontinence affect daily life?* } \\
0 \\
1 \\
2 \\
3 \\
4 \\
5 \\
6 \\
7 \\
8 \\
9 \\
10\end{array}$ & $\begin{array}{l}2(6.9) \\
1(3.4) \\
3(10.3) \\
1(3.4) \\
4(13.8) \\
7(24.1) \\
2(6.9) \\
1(3.4) \\
0 \\
4(13.8) \\
4(13.8)\end{array}$ & $\begin{array}{l}0 \\
0 \\
0 \\
2(25.0) \\
2(25.0) \\
0 \\
0 \\
0 \\
0 \\
3(37.5) \\
1(12.5)\end{array}$ & $\begin{array}{l}2(9.5) \\
1(4.8) \\
3(14.3) \\
1(4.8) \\
2(9.5) \\
5(23.8) \\
2(9.5) \\
1(4.8) \\
0 \\
1(4.8) \\
3(14.3)\end{array}$ \\
\hline $\begin{array}{l}\text { Situations of urine leakage } \\
\text { Before you can get to the toilet } \\
\text { During cough or sneeze } \\
\text { Sleeping } \\
\text { During physical effort or exercise } \\
\text { After urinating and dressing } \\
\text { For no obvious reason } \\
\text { All the time }\end{array}$ & $\begin{aligned} 8 & (27.6) \\
24 & (82.8) \\
4 & (13.8) \\
5 & (17.2) \\
4 & (13.8) \\
2 & (6.9) \\
3 & (10.3)\end{aligned}$ & $\begin{array}{l}4(50.0) \\
6(75.0) \\
1(12.5) \\
1(12.5) \\
1(12.5) \\
1(12.5) \\
1(12.5)\end{array}$ & $\begin{array}{r}4(19.0) \\
18(85.7) \\
3(14.3) \\
4(19.0) \\
3(14.3) \\
1(4.8) \\
2(9.5)\end{array}$ \\
\hline
\end{tabular}

COPD - chronic obstructive pulmonary disease, * numeric scale

Urinary incontinence symptoms: International Consultation on Incontinence Questionnaire-Short Form

The overall prevalence of UI was $31.2 \%(n=29)$. Only women reported this dysfunction and the prevalence among them was $40.3 \%$. UI was present mostly at a frequency of at least once per day (62\%) and in moderate amounts of urine loss (55.2\%) (Table 3). Urine leakage occurred mainly while coughing or sneezing (82.8\%) and $75.3 \%$ had nocturia symptoms.

\section{Multiple regression analyses}

Table 4 shows the results of the multiple regression analyses. The first block (independent variables: sex and age) of the hierarchical multiple linear regression analyses showed a low explanatory power $\left(R^{2}=7 \%\right)$, and only sex was associated with quality of life. In the second block, with the inclusion of comorbidities (UI, hypertension, diabetes, lower back pain, and depression), the explanatory power increased $\left(R^{2}=\right.$ $39 \%$ ), and only having incontinence and depression were significantly associated with quality of life. In the final block, involving the frequency of cough and frequency of dyspnoea, there was a slight increase in the percentage of explained variance $\left(R^{2}=54 \%\right)$. Therefore, only the presence of UI, depression, and higher dyspnoea remained significantly associated with worse quality of life in the multivariate analyses.

\section{Discussion}

The study revealed that the presence of UI, depression, and higher dyspnoea were associated with worse quality of 
Table 4. Association between quality of life among people with chronic respiratory diseases with socio-demographic variables, comorbidities, and frequency of cough and dyspnoea $(n=93)$

\begin{tabular}{|c|c|c|c|c|}
\hline Variables & $B$ & $S E \mathrm{~B}$ & $\beta$ & $R^{2}$ \\
\hline $\begin{array}{l}\text { Step 1: Socio-demographic } \\
\text { Constant } \\
\text { Sex (female) } \\
\text { Age }\end{array}$ & $\begin{array}{r}85.23 \\
-12.84 \\
0.21\end{array}$ & $\begin{array}{r}11.48 \\
6.46 \\
0.15\end{array}$ & $\begin{array}{c}-0.21^{*} \\
0.15\end{array}$ & 0.074 \\
\hline $\begin{array}{l}\text { Step 2: Comorbidities } \\
\text { Constant } \\
\text { Sex } \\
\text { Age } \\
\text { Urinary incontinence } \\
\text { Lower back pain } \\
\text { Arterial hypertension } \\
\text { Diabetes mellitus } \\
\text { Depression }\end{array}$ & $\begin{array}{r}84.55 \\
-3.28 \\
0.20 \\
-21.43 \\
2.00 \\
6.96 \\
2.61 \\
-19.67\end{array}$ & $\begin{array}{r}10.62 \\
6.11 \\
0.14 \\
5.19 \\
4.67 \\
5.64 \\
5.87 \\
5.07\end{array}$ & $\begin{array}{c}-0.05 \\
0.14 \\
-0.40^{\star} \\
0.40 \\
0.13 \\
0.05 \\
-0.37^{\star}\end{array}$ & 0.386 \\
\hline $\begin{array}{l}\text { Step 3: Cough and dyspnoea } \\
\text { Constant } \\
\text { Sex } \\
\text { Age } \\
\text { Urinary incontinence } \\
\text { Lower back pain } \\
\text { Arterial hypertension } \\
\text { Diabetes mellitus } \\
\text { Depression } \\
\text { Frequency of cough } \\
\text { Frequency of dyspnoea }\end{array}$ & $\begin{array}{r}61.03 \\
-0.28 \\
0.24 \\
-16.01 \\
5.39 \\
5.45 \\
2.30 \\
-16.53 \\
-2.12 \\
6.77\end{array}$ & $\begin{array}{r}13.30 \\
5.42 \\
0.13 \\
4.71 \\
4.17 \\
5.09 \\
5.18 \\
4.51 \\
1.26 \\
1.95\end{array}$ & $\begin{array}{c}-0.01 \\
0.17 \\
-0.30^{*} \\
0.11 \\
0.10 \\
0.04 \\
-0.31^{*} \\
-0.16 \\
0.33^{*}\end{array}$ & 0.536 \\
\hline
\end{tabular}

${ }^{*} p<0.05$

life among people with chronic respiratory diseases who attended a healthcare visit in a primary care program in Chile. The Chilean National Program of Adult Respiratory Diseases started in 2001, providing regular control of adult individuals with asthma or COPD at primary care by doctors and physiotherapists. For clinical practice, the results of this study reinforce the importance of an integral approach to managing chronic respiratory patients, as well as treating and preventing incontinence, depression, and other comorbidities in order to improve quality of life and disease control. Respiratory physiotherapists may benefit by referring these patients to pelvic floor physiotherapists and physical activity programs.

According to the literature, more than $80 \%$ of patients with COPD are estimated to have at least one comorbid chronic condition [5]. Owing to the high prevalence of comorbidities, many clinicians find it difficult to follow COPD and asthma guidelines, which results in a lower control of these health problems.

In our cohort, $31 \%$ of participants reported UI with a frequency of at least once per week. The established prevalence for both sexes is in line with the data from the United States (34.9\%) [20]. For female participants, a prevalence of $40.3 \%$ was found, which is in accordance with a Sweden study among women with COPD (49.6\%) [10]. None of the male subjects of our study reported UI, contrary to a Swedish study that indicated a prevalence of $30.3 \%$ among men [10] and to a Japanese study with almost $10 \%$ of men with COPD reporting UI symptoms [21]. Overall, the literature shows that the prevalence of $\mathrm{UI}$ is higher in women (ranging from $18 \%$ to $80 \%$ ) than in men (about 3-11\%) [22]. UI in men is mainly associated with prostate surgery, trauma, or neurological injury; this difference might be due to these characteristics, which were not reported in the present study.

In our study, UI was associated with impaired quality of life. In patients with UI, the quality of life score was lower by need for UI management in individuals with chronic respiratory diseases in the context of primary care. The UI type most self-reported among the participants was stress UI. Around $83 \%$ demonstrated UI during coughing or sneezing. This is intuitively explained by the constant increases in intra-abdominal pressure during coughing and sneezing in patients with respiratory disorders, which have been mentioned as risk factors for $\mathrm{UI}[10,11]$. It is already known that pelvic floor muscle training is the first line of treatment for UI symptoms and consequently improves the quality of life [23]. Therefore, this finding suggests that if the patients apply conservative treatment for UI, which has no side effects, their quality of life should improve.

The presence of depressive symptoms was also associated with impaired quality of life. The findings demonstrated a quality of life score lower by 16.53 points in participants with depressive symptoms as compared with those without depression. Mental health disorders, such as depression and anxiety, are extremely common in individuals with COPD [5, 6]. According to Cully et al. [4], these disorders are the most noticeable factors associated with quality of life outcomes in people with COPD. A meta-analysis which included a pooled analysis of 5552 participants with COPD and 5211 controls identified a prevalence of depression of $27.1 \%$ (95\% confidence interval [Cl]: 25.9-28.3\%) in COPD patients and 10.0\% (95\% Cl: $9.2-10.8 \%$ ) in the control group, with a pooled odds ratio of $3.74(95 \% \mathrm{Cl}: 2.4-5.9)$ [6]. It has been argued that depression is a recognized determinant of quality of life and that anxiety precedes or coexists with depression, coinciding in symptoms [24]. This study, however, did not evaluate anxiety.

Regarding sex, when we included only socio-demographic factors (age and sex) in the regression model, only females were associated with decreased quality of life, although with a low explanatory power $\left(R^{2}=0.074\right)$. A German study among asthma patients showed that being female was associated 
with worse scores in physical and mental quality of life domains [2]. Our results indicated yet that for each 1-unit increment on the mMRC dyspnoea scale (with higher scores meaning less severe dyspnoea), there was an increase by 6.77 points in the quality of life score (reflecting worse quality of life). Another recent study also found that higher dyspnoea was associated with decrements ranging from 3.9 to 8.2 points in all 8 domains of the ICIQ-UI-SF questionnaire health profile after adjustment for socio-demographics, general health characteristics, and length of COPD diagnosis [25]. According to these authors, of all the symptoms of COPD, dyspnoea is the most dominant and defining one [24].

\section{Limitations}

The present study had some limitations. First, the small sample size impeded the separate analysis COPD and asthma patients. Besides, we did not use a validated questionnaire to identify depression symptoms. It is also unknown if the comorbidity factors emerged before or after the respiratory disorders. We suggest that future studies include a larger sample size and apply a validated questionnaire or a psychiatric diagnosis to determine depression symptoms.

\section{Conclusions}

In the context of these results, we consider that health professionals might play an important role in improving the quality of life among asthma and COPD patients through comprehensive care plans to deliver more integral care. Our observations also suggest that patients with respiratory symptoms concomitant with UI, higher dyspnoea, or depression have an even worse quality of life and should therefore be assessed and treated comprehensively. Physiotherapists managing these patients should pay attention to the comorbidities in order to offer integrated treatments.

\section{Disclosure statement}

No author has any financial interest or received any financial benefit from this research.

\section{Conflict of interest}

The authors state no conflict of interest.

\section{References}

1. Adeyeye OO, Adewumi TA, Adewuya AO. Effect of psychological and other factors on quality of life amongst asthma outpatients in Lagos, Nigeria. Respir Med. 2017; 122:67-70; doi: 10.1016/j.rmed.2016.12.002.

2. Böhmer MM, Brandl M, Brandstetter S, Finger T, Fischer W, Pfeifer $\mathrm{M}$, et al. Factors associated with generic health-related quality of life in adult asthma patients in Germany: cross-sectional study. J Asthma. 2017;54(3): 325-334; doi: 10.1080/02770903.2016.1206563.

3. Chile Ministry of Health. AUGE clinical guidelines: chronic obstructive pulmonary disease [in Spanish]. Santiago: MINSAL; 2013.

4. Cully JA, Graham DP, Stanley MA, Ferguson CJ, Sharafkhaneh A, Souchek J, et al. Quality of life in patients with chronic obstructive pulmonary disease and comorbid anxiety or depression. Psychosomatics. 2006;47(4): 312-319; doi: 10.1176/appi.psy.47.4.312.

5. Putcha N, Drummond MB, Wise RA, Hansel NN. Comorbidities and chronic obstructive pulmonary disease: prevalence, influence on outcomes, and management.
Semin Respir Crit Care Med. 2015;36(4):575-591; doi: 10.1055/s-0035-1556063.

6. Matte DL, Pizzichini MMM, Hoepers ATC, Diaz AP, Karloh M, Dias M, et al. Prevalence of depression in COPD: a systematic review and meta-analysis of controlled studies. Respir Med. 2016;117:154-161; doi: 10.1016/j. rmed.2016.06.006.

7. Frei A, Muggensturm P, Putcha N, Siebeling L, Zoller M, Boyd CM, et al. Five comorbidities reflected the health status in patients with chronic obstructive pulmonary disease: the newly developed COMCOLD index. J Clin Epidemiol. 2014;67(8):904-911; doi: 10.1016/j.jclinepi.2014.03.005.

8. Chile Ministry of Health. AUGE clinical guidelines: bronchial asthma in adults [in Spanish]. Santiago: MINSAL; 2013.

9. Beeckmans N, Vermeersch A, Lysens R, Van Wambeke P, Goossens N, Thys T, et al. The presence of respiratory disorders in individuals with low back pain: a systematic review. Man Ther. 2016;26:77-86; doi: 10.1016/j.math. 2016.07.011.

10. Hrisanfow E, Hägglund D. The prevalence of urinary incontinence among women and men with chronic obstructive pulmonary disease in Sweden. J Clin Nurs. 2011;20(13-14):1895-1905; doi: 10.1111/j.1365-2702. 2010.03660.x.

11. Van Gerwen M, Schellevis F, Lagro-Janssen T. Comorbidities associated with urinary incontinence: a casecontrol study from the Second Dutch National Survey of General Practice. J Am Board Fam Med. 2007;20(6): 608-610; doi: 10.3122/jabfm.2007.06.070151.

12. Divo M, Cote C, de Torres JP, Casanova C, Marin JM, Pinto-Plata V, et al. Comorbidities and risk of mortality in patients with chronic obstructive pulmonary disease. Am J Respir Crit Care Med. 2012;186(2):155-161; doi: 10.1164/rccm.201201-0034OC.

13. Steyerberg EW. Clinical prediction models: a practical approach to development, validation, and updating. New York: Springer; 2010.

14. Güell R, Casan P, Sangenís M, Morante F, Belda J, Guyatt $\mathrm{GH}$. Quality of life in patients with chronic respiratory disease: the Spanish version of the Chronic Respiratory Questionnaire (CRQ). Eur Respir J. 1998;11(1): 55-60; doi: 10.1183/09031936.98.11010055.

15. Serón P, Riedemann P, Sanhueza A, Doussoulin A, Villarroel P. Validation of the chronic respiratory questionnaire in Chilean patients with chronic airflow limitation. Rev Med Chil. 2003;131(11):1243-1250.

16. Bestall JC, Paul EA, Garrod R, Garnham R, Jones PW, Wedzicha JA. Usefulness of the Medical Research Council (MRC) dyspnoea scale as a measure of disability in patients with chronic obstructive pulmonary disease. Thorax. 1999;54(7):581-586; doi: 10.1136/thx.54.7.581.

17. Avery K, Donovan J, Peters TJ, Shaw C, Gotoh M, Abrams P. ICIQ: a brief and robust measure for evaluating the symptoms and impact of urinary incontinence. Neurour Urodyn. 2004;23(4):322-330; doi: 10.1002/ nau.20041.

18. Busquets CM, Serra TR. Validation of a Spanish version of the International Consultation on Incontinence Questionnaire Short-Form. Rev Med Chil. 2012;140(3): 340-346; doi: 10.4067/S0034-98872012000300009.

19. Field A. Discovering Statistics Using IBM SPSS Statistics [in Portuguese]. Porto Alegre: Artmed; 2009.

20. Schnell K, Weiss CO, Lee T, Krishnan JA, Leff B, Wolff JL, et al. The prevalence of clinically-relevant comorbid con- 
ditions in patients with physician-diagnosed COPD: a cross-sectional study using data from NHANES 19992008. BMC Pulm Med. 2012;12:26; doi: 10.1186/14712466-12-26.

21. Hirayama F, Lee AH, Binns CW, Taniguchi H, Nishimura $\mathrm{K}$, Kato $\mathrm{K}$. Urinary incontinence in men with chronic obstructive pulmonary disease. Int J Urol. 2008;15(8): 751-753; doi: 10.1111/j.1442-2042.2008.02093.x.

22. Nitti VW. The prevalence of urinary incontinence. Rev Urol. 2001;3(Suppl. 1):S2-S6.

23. Dumoulin C, Adewuyi T, Booth J, Bradley C, Burgio K, Hagen $S$, et al. Adult conservative management. In: Abrams P, Cardozo L, Wagg A, Wein A (eds.), Incontinence. $6^{\text {th }}$ International Consultation on Incontinence, Tokyo, September 2016. Bristol: ICS, ICUD; 2017; 14431628.

24. Polikandrioti M, Panoutsopoulos G, Tsami A, Gerogianni G, Saroglou S, Thomai E, et al. Assessment of quality of life and anxiety in heart failure outpatients. Arch Med Sci Atheroscler Dis. 2019;4:e38-e46; doi: 10.5114/ amsad.2019.84444.

25. Gruenberger JB, Vietri J, Keininger DL, Mahler DA. Greater dyspnea is associated with lower health-related quality of life among European patients with COPD. Int J Chron Obstruct Pulmon Dis. 2017;12:937-944; doi: 10.2147/COPD.S123744. 